
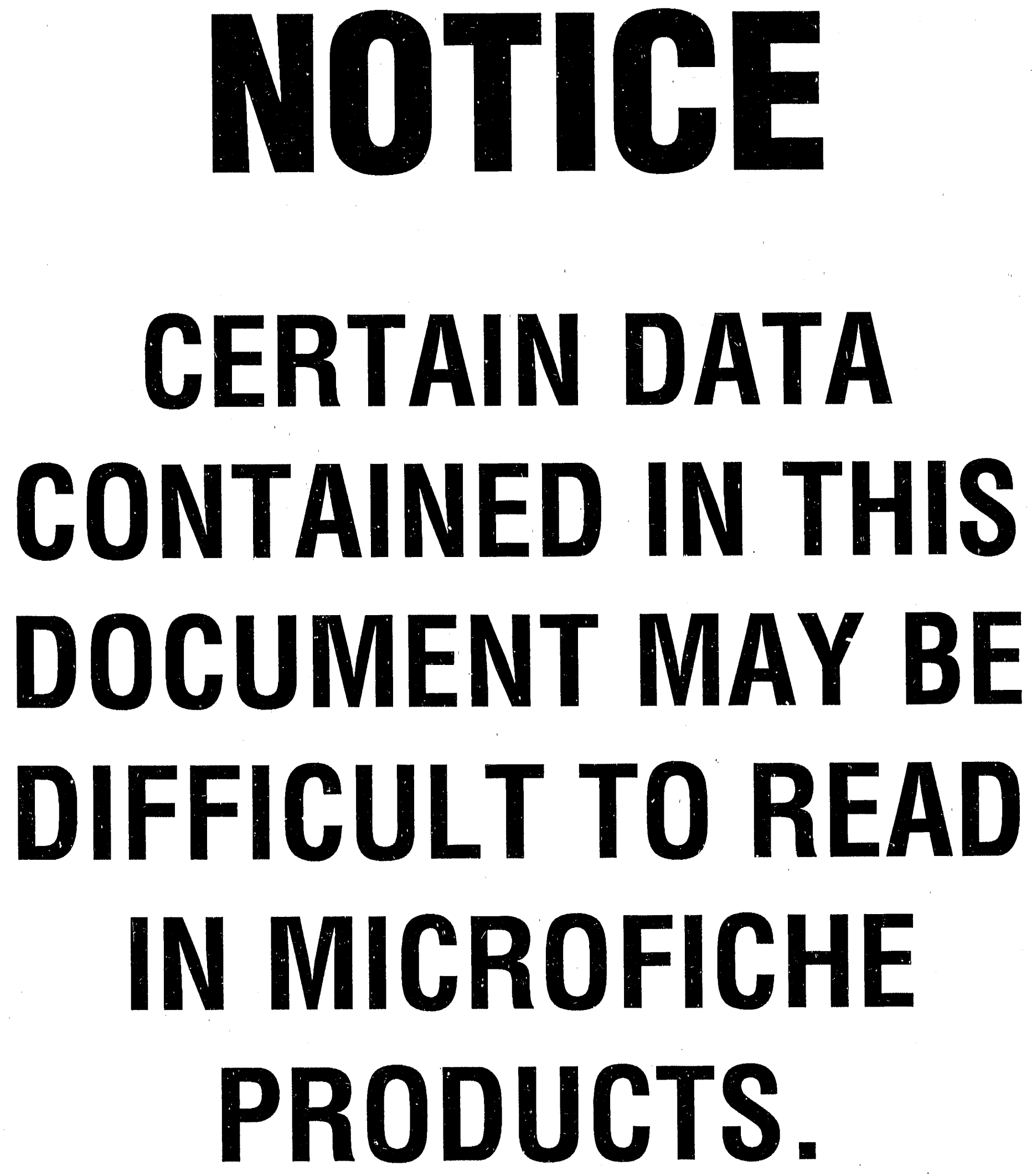


\title{
An Historical Mullite Fiber-Reinforced Ceramic Composite: Characterization of the \\ 'Wootz' Crucible Refractory
}

\author{
T.L. Lowe \\ Department of SSEAS \\ University of California \\ Berkeley, California 94720 \\ and \\ N. Merk and G. Tl omas \\ National Center for Electron Microscopy \\ Lawrence Berkeiey Laboratory \\ University of California \\ Berkeley, CA 94720
}




\title{
AN HISTORICAL MULLITE FIBER-REINFORCED CERAMIC COMPOSITE: CHARACTERIZATION OF THE 'WOOTZ' CRUCIBLE REFRACTORY
}

Thelma L. Lowe*, Nima Merk** and Gareth Thomas**

*Department of SSEAS, University of California, Berkeley, CA 94720

**National Center for Electron Microscopy

Lawrence Berkeley Laboratory

1 Cyclotron Road

Berkeley, CA 94720

\begin{abstract}
Since at least the sixteenth century, the 'wootz' ultra-high carbon white cast-iron ingot was produced in India by melting or carburising iron in a crucible. This ingot was forced into sword blades of so-called 'Damascus' steel. The charged crucible was fired in a long (24-hour) single cycle at high temperature $\left(1150-1250^{\circ} \mathrm{C}\right)$ in a strongly reducing atmosphere. Raw materials for the refractory vessel are clay and 'coked' rice husks. At high temperatures, two phases reinforce the glassy matrix: cristobalite relics of rice husks and a network of mullite crystals. This paper characterizes the microstructure and chemistry of the mullite network in the glassy matrix by means of a combination of techniques: optical microscopy, XRD, SEM, TEM with EDS, and HREM. Introduction to the 'Wootz' Crucible and Process

The Indian 'wootz' white cast-iron ingot was melted in a closed bowl-shaped crucible at about $1200^{\circ} \mathrm{C}$. The production of 'wootz' is a batch process (as are most 'special steels'). The crucibles are not pre-fired. They were used once to melt the metal, then cooled and broken to retrieve the ingot. The charcoal fire in the furnace died down and the crucibles were removed to cool slowly to produce the characteristic coarse crystalline texture of the 'wootz' ingot and of 'Damascus' steel [1,2]. Thermal properties controlled by high porosity and by orientation of the rice husks during fabrication favor
\end{abstract}


low cooling and controlled crystallization [4]. The crucible vessel is refractory and insulating; the ceramic was designed for high performance in a highly specified metallurgical industry.

The physical requirements of mechanical and chemical stability are satisfied. The vessel walls were not attacked by the furnace atmosphere nor by molten metal because interior and exterior surfaces are covered with a silica-rich slag during the firing cycle. Further, the furnace fuel was entirely charcoal and the refractory composition is rich in carbon [2]. Strongly reducing firing conditions inhibits iron-silica reactions which degrade refractory performance in iron processing applications and high carbon content makes the vessel surfaces practically unwettable. Glass formation and mullite crystallization within vessel walls are the dominant chemical reactions. The vessel is a fiber-reinforced composite ceramic; although stability may be influenced by the coherent silica (cristobalite) rice husk relics, mechanical strength at production temperatures is mainly a result of a dense load-bearing network of accicular mullite crystals in a high-silica glassy matrix.

Mullite networks are extremely common in clay-based ceramics. In the same sense as triaxial porcelain, the 'wootz' crucible is a mullite fiber-reinforced composite. The alumino-silicate mullite (which has a c-axis growth habit) forms easily and early in natural clay-based ceramics fired above $1000^{\circ} \mathrm{C}$ [5]. The basic composition of this range of materials is quartz, clay and feldspar; a melt of this composition fired in the range of $1000^{\circ} \mathrm{C}$ to $1250^{\circ} \mathrm{C}$ forms mullite crystals and a viscous high-silica glass [7].

Samples of likely ceramic raw material from the Indian research area are being investigated by particle-size distribution analysis and XRD of the mineral and clay fractions. Preliminary results indicate that the material which is weathered from granitegneiss is 'clay' (dominant fraction less than $2.0 \mu \mathrm{m}$ ) and that the basic composition is effectively 'doped' with alumina from the feldspars and micas in the silt fraction. Melts of these compositions have the process advantage of a "long firing range and low sensitivity to compositional variations". The sequence of reactions of the fluid phases with quartz at 
higher temperatures results in the evolution of a glass of continuously increasing viscosity as a result of increasing silica content [6]. Reactions within the glassy phase of the crucible wall further increase viscosity by the removal of iron oxide as a flux; it is reduced to numerous microscopic to macro-size iron 'prills' [2]. Another component that effectively increases viscosity (that is, reduces 'creep') is the crumpled graphite inclusions in the glassy matrix which may mechanically interfere with fluid flow (Fig. 11).

Mullite crystals "as a bonding phase exhibit refractoriness, low creep rate, low thermal expansion and thermal conductivity, good chemical and thermal stability, and good toughness and strength" [3]. Mullite prepared from stoichiometric xerogels and other pure starting materials requires high processing temperatures and expensive raw materials. Crystallization of mullite from natural clays, fired at traditional ceramic processing temperatures, is facilitated by mineralizers such as Fe and Ti ('impurities' in commercial clays) which enhance mullitization and may affect grain growth [8]. These mineralizers "should also optimize mullite yield at lower temperatures" [3].

Experimental Procedures

Transmission optical microscopy was done on $30 \mathrm{~mm}$ polished thin sections in a Nikophot petrographic microscope in the Department of Earth Sciences, UCB. Refractory samples were coarsely crushed and leached for 2 to 8 hours in $40 \% \mathrm{HF}$ at $23^{\circ} \mathrm{C}$ to remove the glassy phase and cristobalite for study of the mullite network.

An X-ray (XRD) diffraction pattern of a leached, ground crucible wall sample was obtained on a Siemens Theta-Two Theta instrument at LBL, UCB. Carbon and gold coated crushed powders were used for scanning electron microscopy on a JEOL 35CX in the Department of MSME. Finely ground powders of bulk and leached crucible samples, dispersed on a holey carbon coated copper grid, were examined by transmission electron microscopy (TEM). TEM observation and analysis were performed on a JEOL 200CX analytical electron microscope equipped with a high angle X-ray detector using a $20 \mathrm{~nm}$ beam size for energy dispersive spectroscopy point-analysis. High resolution electron 
microscopy (HREM) was carried out on the ARM-1000 instrument at the National Center for Electron Microscopy (NCEM), Lawrence Berkeley Laboratory, UCB.

Characterization of the Fired 'Wootz" Crucible

The crucible refractory ceramic is a rich black color, uniformly very porous, lightweight and hard material. Some physical properties have been determined on single refractory samples:

\begin{tabular}{|c|c|c|}
\hline \multicolumn{3}{|c|}{$\underset{(2 \text { wall samples) }}{\text { Porosity [9] }}$} \\
\hline $\begin{array}{l}\text { Open porosity } \\
\text { Closed porosity } \\
\text { Total }\end{array}$ & $\begin{array}{l}29.91 \% \\
\frac{13.53}{43.44 \%}\end{array}$ & $\begin{array}{l}27.33 \% \\
\frac{13.60}{40.93 \%}\end{array}$ \\
\hline Average & & \\
\hline
\end{tabular}

Specific Density [9]

$\begin{array}{llll} & & & \text { Average } \\ \text { Apparent } & 1.483 & 1.508 & 1.495 \\ \text { True } & 2.622 & 2.553 & \underline{2.587}\end{array}$

Thermal Conductivity [10]

Average of 14 determinations on 7 samples of walls and bases-- $0.49 \mathrm{Wm}^{-1} \mathrm{k}^{-1}$

\section{Carbon Content of Crucible Refractory Ceramic}

$\begin{array}{ll}\text { By thermogravimetry [11] } & 1.5 \mathrm{wt} \% \mathrm{C} \\ \text { By colorimetry [12] } & 5.6 \mathrm{wt} \% \mathrm{C}\end{array}$

From the XRD pattern of the orthorhombic mullite the lattice parameters are: $a=0.76 \mathrm{~nm}, b=0.75 \mathrm{~nm}, c=0.29 \mathrm{~nm}$ (Fig. 1). Using elemental chemical composition measured by EDS, the mullite composition was determined as 2:1 (Fig. 2). Chemical composition of the glassy phase was also determined by EDS (Fig. 3).

The uniformly porous glassy black surface of a polished section shows, at low magnification, two phases of porosity; linear roughly oriented voids formed by the 'coked' rice husks (the cristobalite husk walls retain their structure in the voids) and smaller 
spherical voids produced by gas evolution from the reduction of $\mathrm{Fe}_{2} \mathrm{O}_{3}$ to $\mathrm{Fe}$ metal. Numerous sections of iron prills are dispersed on the polished surface.

A polished thin section under plane-polarized light is isotropic except for a few fractured and reacted quartz grains (probably cristobalite). The mullite crystals are thinner than 30 microns and are thus obscured in the isotropic glass. Under plane light, the complex microstructure is clearly visible even at $100 \mathrm{X}$ and consists of the following phases (Figs. 4, 5, 6): (1) A dense pattern of accicular mullite crystals--coarse crystals in the reacted feldspar grains and finer crystallites hardly resolved in the fluid phase formed from clay (mf, mc). (2) Particulate carbon 'clouds' in the glass form a roughly reticulated pattern around mullite crystallite aggregates. Fine fragments of carbonized plant materials and finely divided carbon are associated with the rice husks (c). (3) Quartz grains, shattered, some with reaction rims in the glassier areas (q). (4) Clear glassy areas, often around pores where the fluid phase flows but does not flow away (g). (5) Dark circles of wide size-range are iron prills and pores (pr,po). (6) Sectioned rice husks, very likely cristobalite, with associated dense carbon accumulation (rh).

The three-dimensional disposition of the mullite crystals in a dense network around a pore is displayed in a SEM back-scattered image of a leached sample (Fig. 7). The apparent wide particle-size distribution creates a maximum packing condition which immobilizes the pore and stabilizes the vessel.

A conventional amplitude contrast TEM micrograph (Fig. 8) of a bulk sample shows the microstructure of the glassy matrix containing mullite fibers. After leaching the glassy phase, finely ground powder of pure submicroscopic mullite whiskers (free of carbon burned off at $800^{\circ} \mathrm{C}$ for 1 hour) were studied in the TEM. The range of fiber morphologies is shown in Fig. 9

A high resolution [110] orientation of a very thin mullite fiber $(\leq 20 \mathrm{~nm})$ is presented in Fig. 10. Work on the nature of glass-mullite interface is underway. High resolution also enables study of the graphite distribution within the glassy phase (Fig. 11). 


\section{Discussion}

Developments in research on 'engineered' high-performance ceramics have been in the direction of homogeneous microstructures which require highly controlled starting materials and processes. More recently there is an interest in clay-based ceramic design of microstructures of controlled complexity. The composition of natural raw materials contributes mineralizers and finely divided and reactive components which can form desirable properties at lower temperatures. Structures composed of mullite networks crystallized from natural clays are a possible solution to the problem of strengthening composite materials. The 'wootz' crucible refractory is a good example of this category of high-performance material. Our furcher investigation of this material will include chemistry and quantification of the glassy phase and of the temperature conditions under which the crucibles were used. Samples from 14 sites of 'wootz' production (identified during field work 1987-89) will be studied for variability in composition and microstructure.

It is apparent from Figs. 4, 8 and 9 that the microstructure of the mullite network is self-similar at increasing scales and that the concept of a fractal dimension and of 'percolation' may be useful to characterize the mechanical behavior of this network at high temperatures. We shall be working on the development of appropriate images and measurements for determining this dimension [13].

\section{Acknowledgements}

We wish to thank the Department of Archaeology and Museums of the Government of Andhra Pradesh, Hyderabad and the Archaeological Survey of India, New Delhi, India for the opportunity to study these materials. This research was supported in part by the Director, Office of Energy Research, Office of Basic Energy Sciences, Materials Science Division, U. S. Department of Energy under Contract No. DE-AC-03-76SF00098.

\section{References and Notes}

1. H. W. Voysey, Description of the native manufacture of steel in India, J. Asiatic Society, Bengal 1, 245-247 (1832). 
2. T. L. Lowe, Refractories in high-carbon iron processing: a preliminary study of the Deccani Wootz-making crucible, in Ceramics and Civilization III. Proc. Amer. Cer. Soc., Pittsburgh, April 1987, in press.

3. A. J. Skoog and R. E. Moore, Ceram. Bull. 64, 1180-1185 (1988). For a summary list of these properties of mullite, see Tables I, II, III, IV.

4. T. L. Lowe, Solidification and the crucible processing of Deccani ancient steel, in Solidification and Materials Processing, Proc. Indo.-U.S. Conf., Defence Metallurgical Research Laboratory, Hyderabad, Andhra Pradesh, India, January 1988, IBH and Oxford Press, New Delhi (in press).

5. T. D. McGee, J. Amer. Cer. Soc. 49, 87-90 (1966).

6. W. D. Kingrey, H. K. Bowen and D. R. Uhlmann, Introduction to Ceramics, 2nd ed. (John Wiley \& Sons, Inc. New York, 1976), p. 540.

7. F. Onike, G. D. Martin and A. C. Dunham, Mat. Sci. For. 7, 738 (1986).

8. S. M. Johnson, J. A. Pask and J. S. Moya, J. Amer. Cer. Soc. 65, 31 -35 (1982).

9. Done at Central Cer. Res. Inst. Calcutta, India.

10. Done at Nat. Geoph. Res. Inst. Hyderabad, Andhra Pradesh, India. Instrument, modified divided bar, mean $\mathrm{T}=32^{\circ} \mathrm{C}$. Courtesy of Dr. M. L. Gupta.

11. Done at Schmidt Festkorper Institut, Leoben, Austria. Courtesy of Dr. Gerhard Sperl.

12. Done at the Inst. for Advanced Study in Archaeology, Deccan College, Pune, Maharashtra, India. Courtesy of Dr. V. Gogte.

13. E. Guyon and S. Roux, Les materiaux heterogenes. La Recherche 191, September 1987. 


\section{Figure Captions}

Fig. 1. XRD pattern on leached mullite fibers showing orthorhombic structure.

Fig. 2. EDS point analysis of a leached mullite fiber using ultra-thin window detector for oxygen. Significant mineralizers are present.

Fig. 3. EDS point analysis on the high-silica glassy phase adjacent to a mullite crystal. It approaches a mica composition.

Fig. 4. $600 \mathrm{X}$ magnification of mullite crystals in a densly packed network texture.

Phases are identified.

Fig. 5. Plane light micrograph of the refractory composition showing the 'coked' rice husk component (20X).

Fig. 6. 100X magnification shows phase relations of the ceramic composition.

Fig. 7. Back-scattered SEM image of mullite network.

Fig. 8. TEM micrograph and the SADP of a bulk sample showing mullite network at high magnification.

Fig. 9. TEM micrograph of leached refractory sample showing wide size distribution of mullite fiber crystals.

Fig. 10. High resolution electron micrograph of a mullite fiber along [110] direction. The insets are the optical diffraction and the simulated image at a thickness of $5 \mathrm{~nm}$ and a defocus of $-60 \mathrm{~nm}$.

Fig. 11. High resolution electron micrograph of crumpled two-dimensional particulate graphite dispersed in the glassy matrix. 


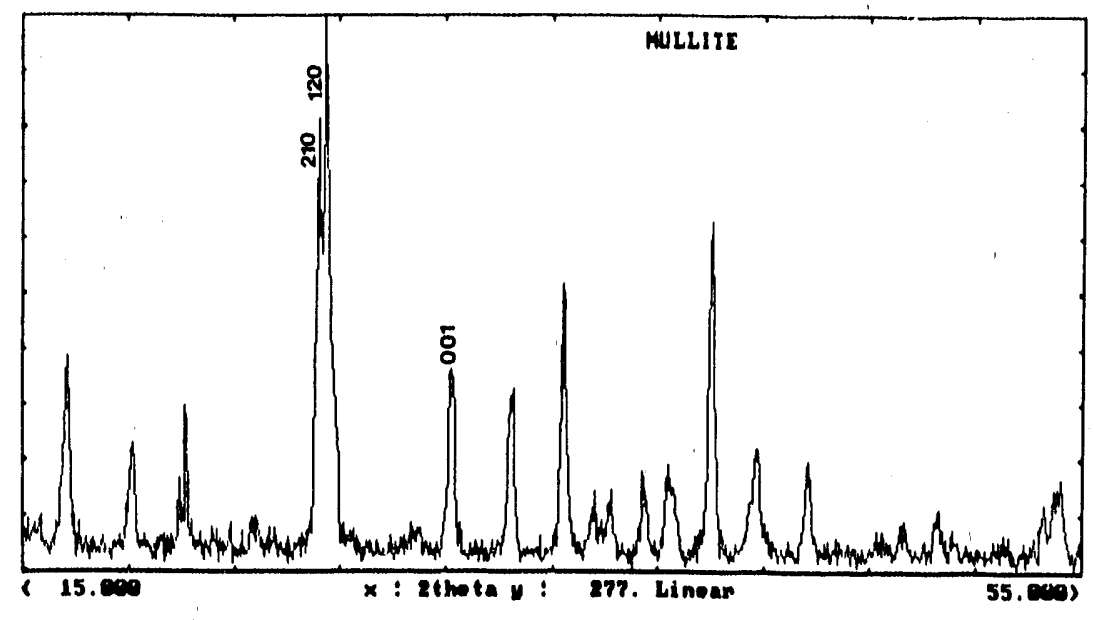

XBL $904-1330$

Fig. 1

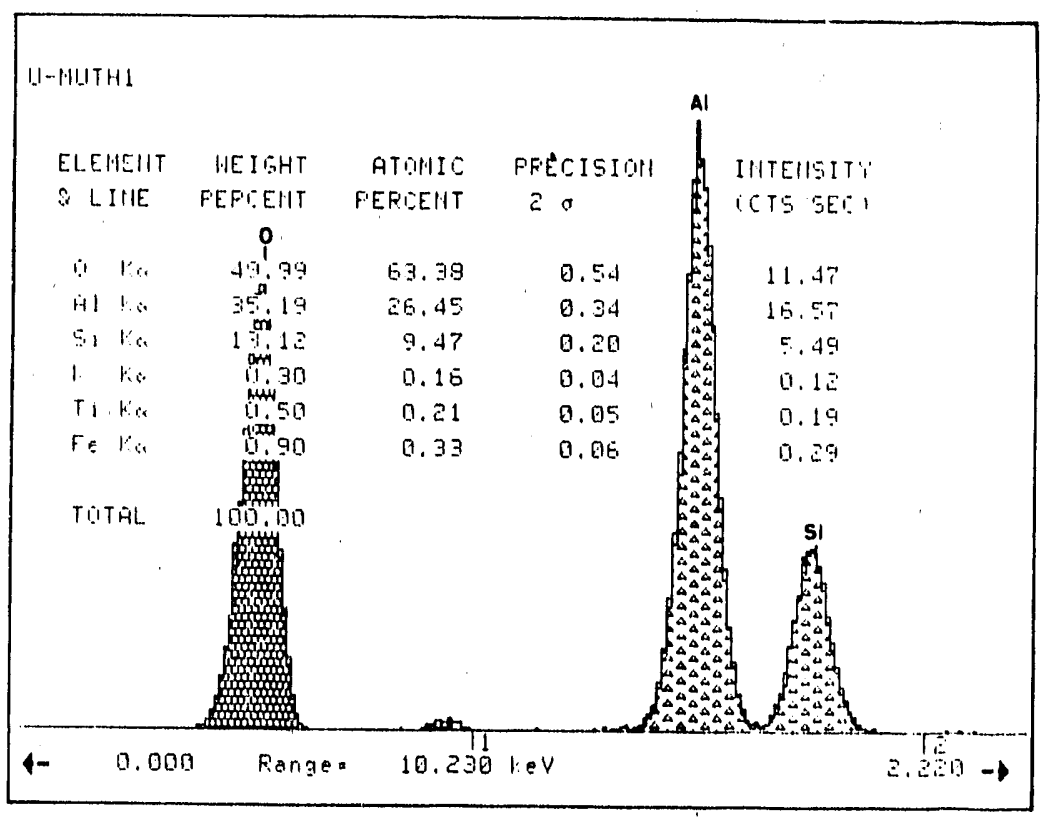

XBL $904-1328$

Fig. 2 


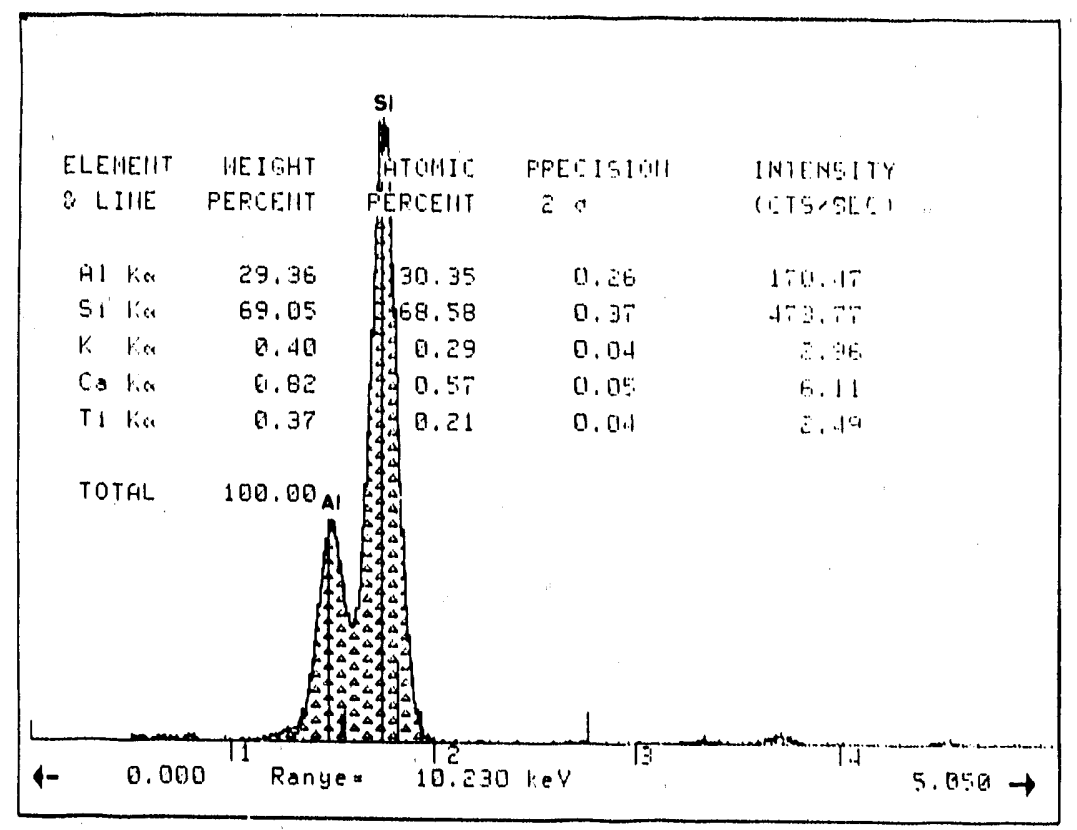

XBL 904-1329

Fig. 3

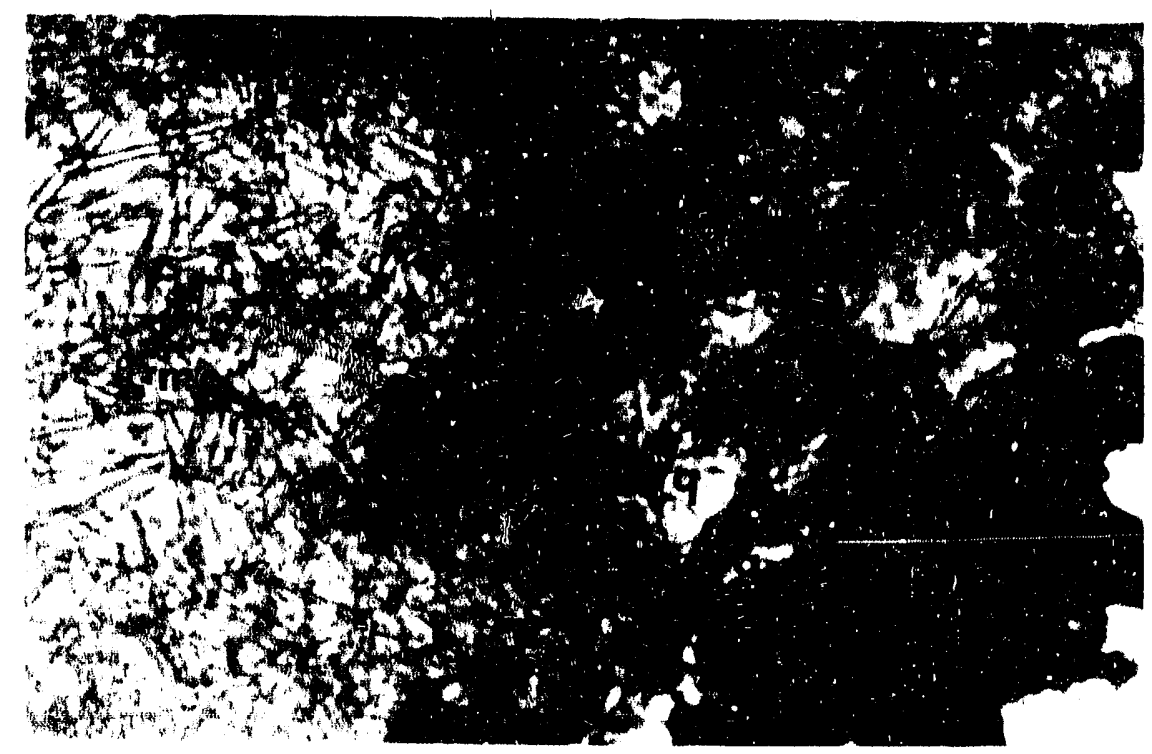




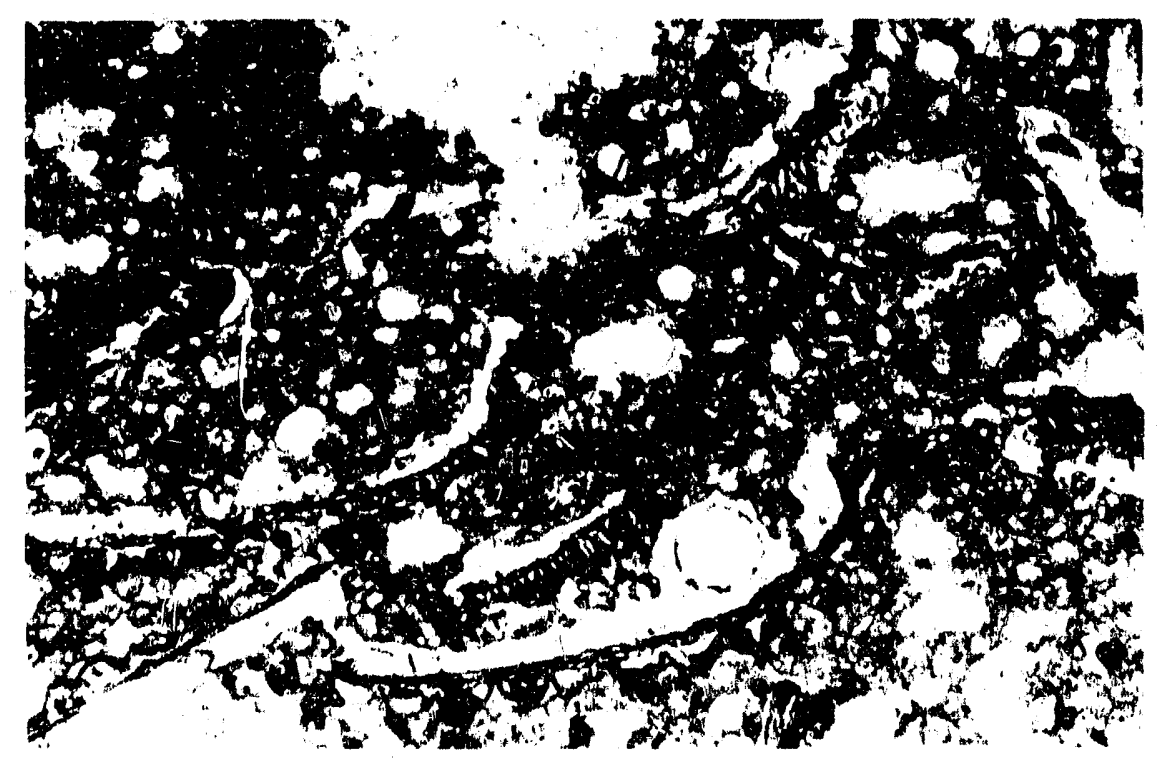

XBB $900-8446$

Fig. 5

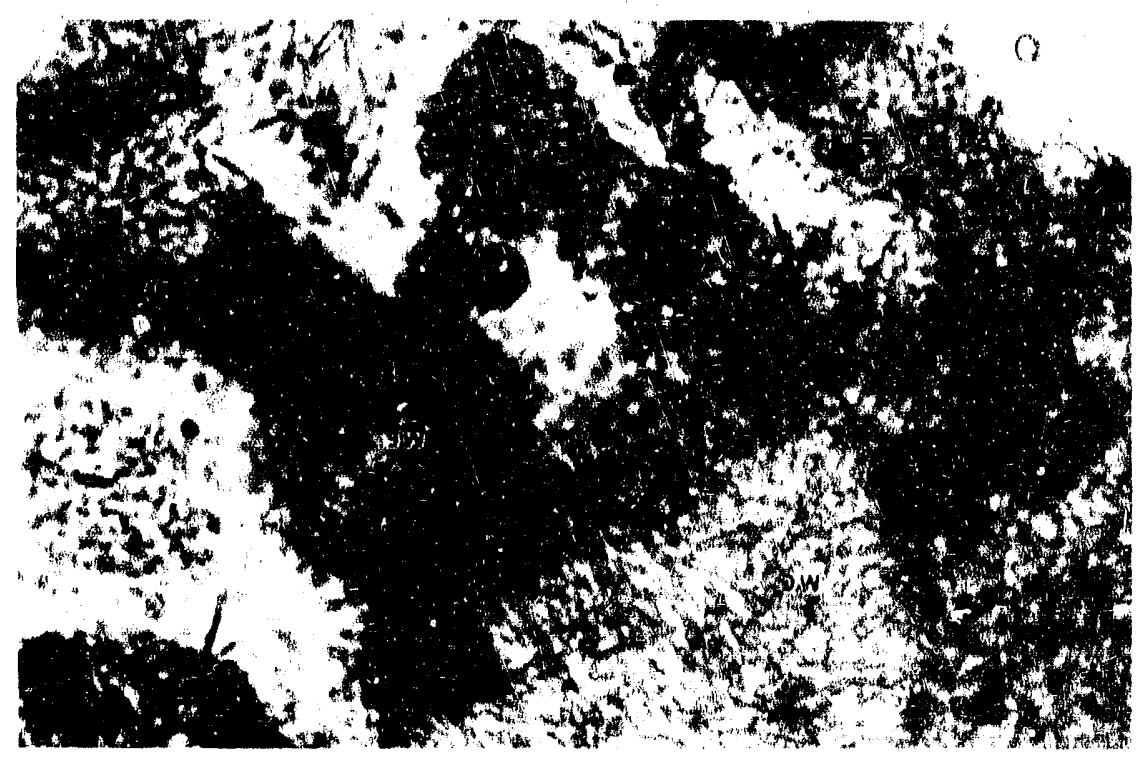




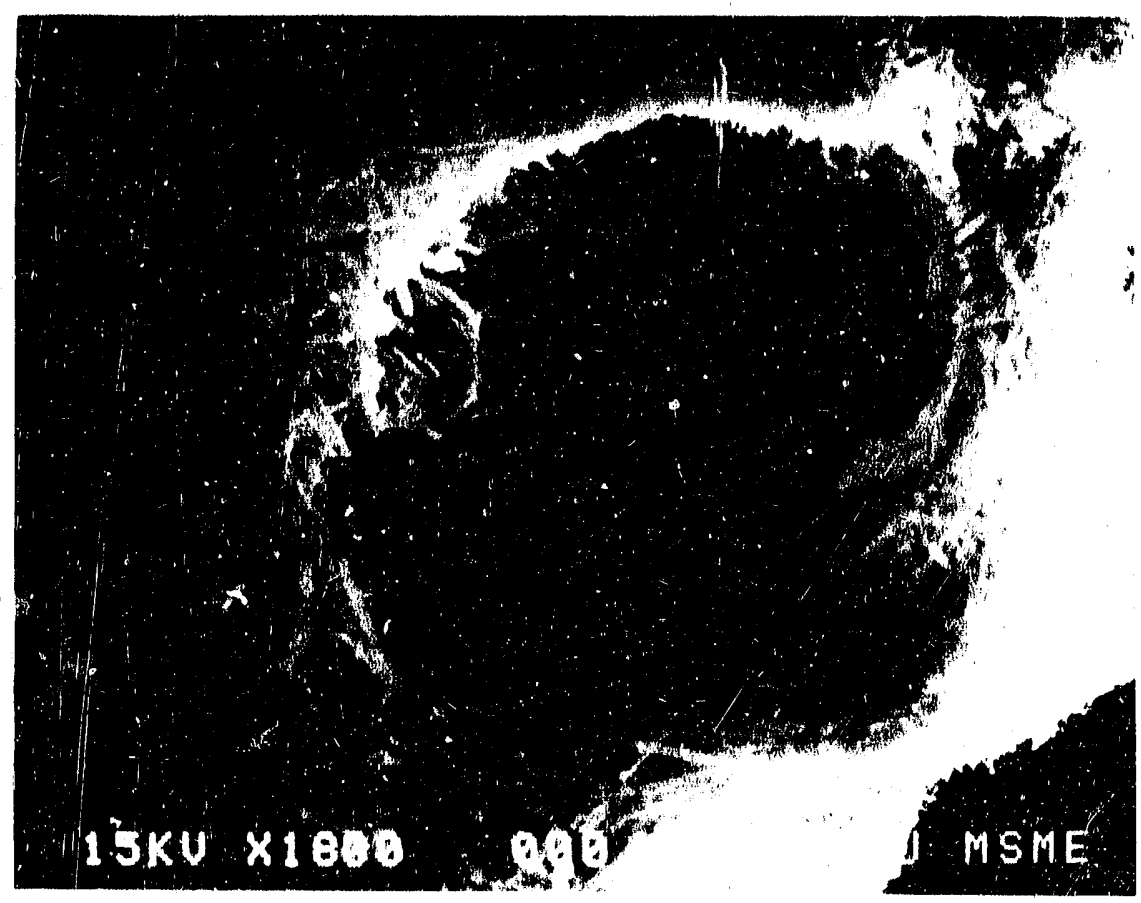

XBB $904-3027$

Fig. 7

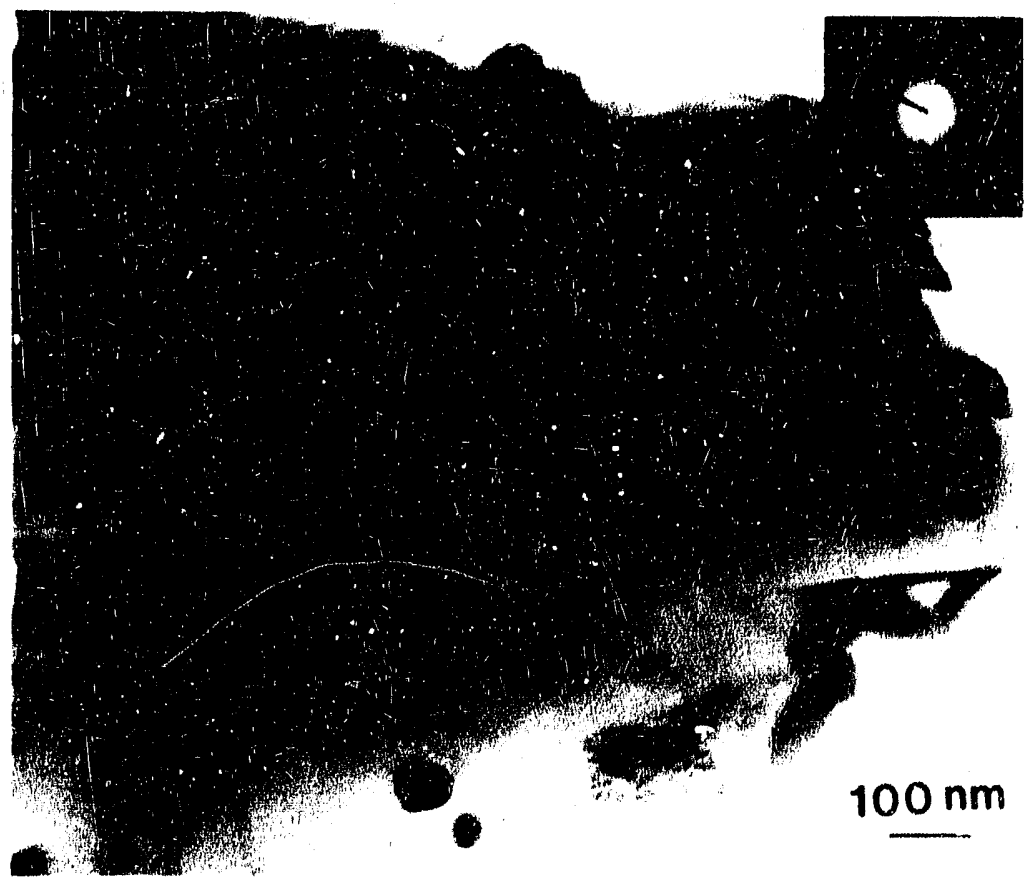

Fig. 8

XBB $904-3019$ 


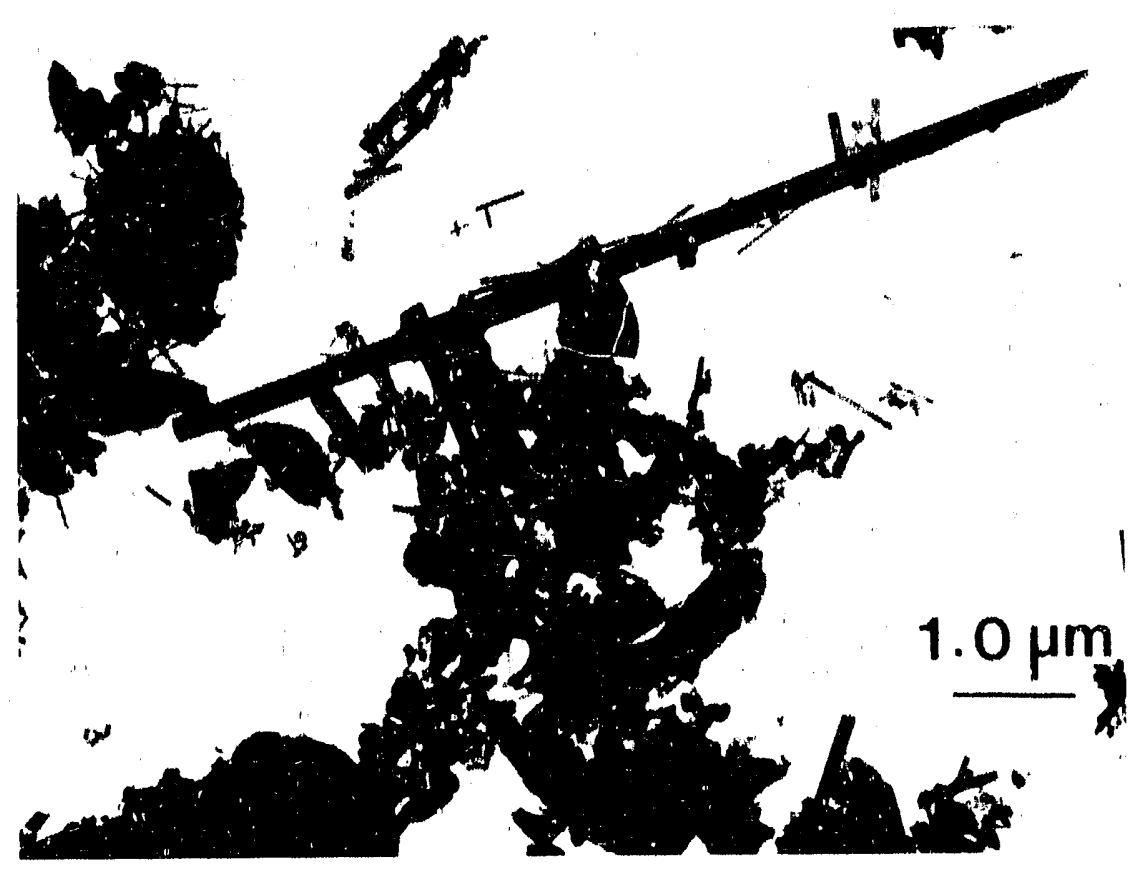

Fig. 9

XBB 904-3021

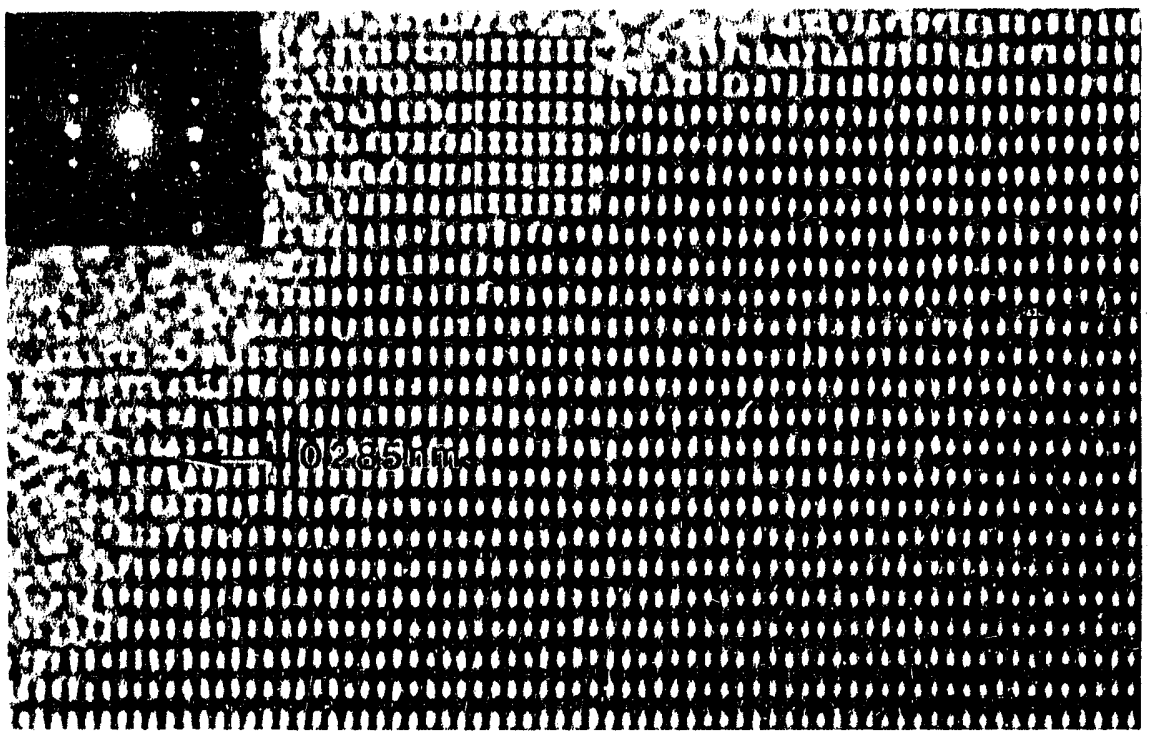

Fig. 10 


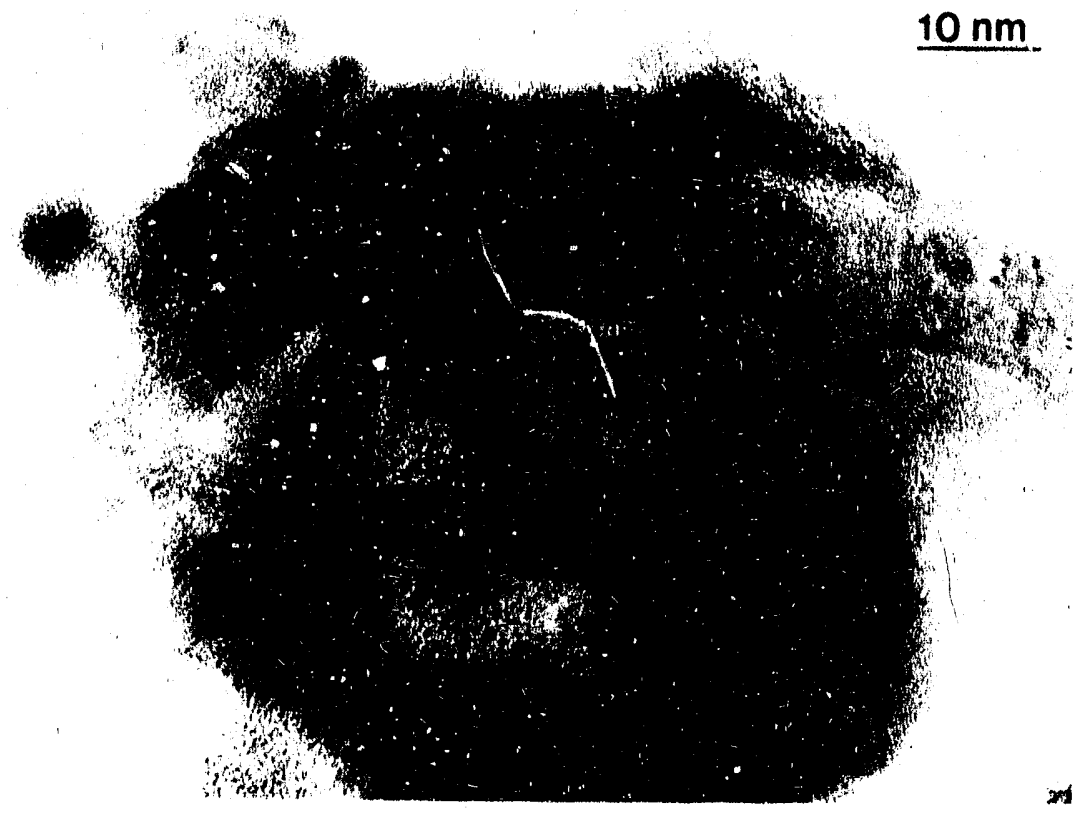

Fig. 11

XBB $904-3020$ 

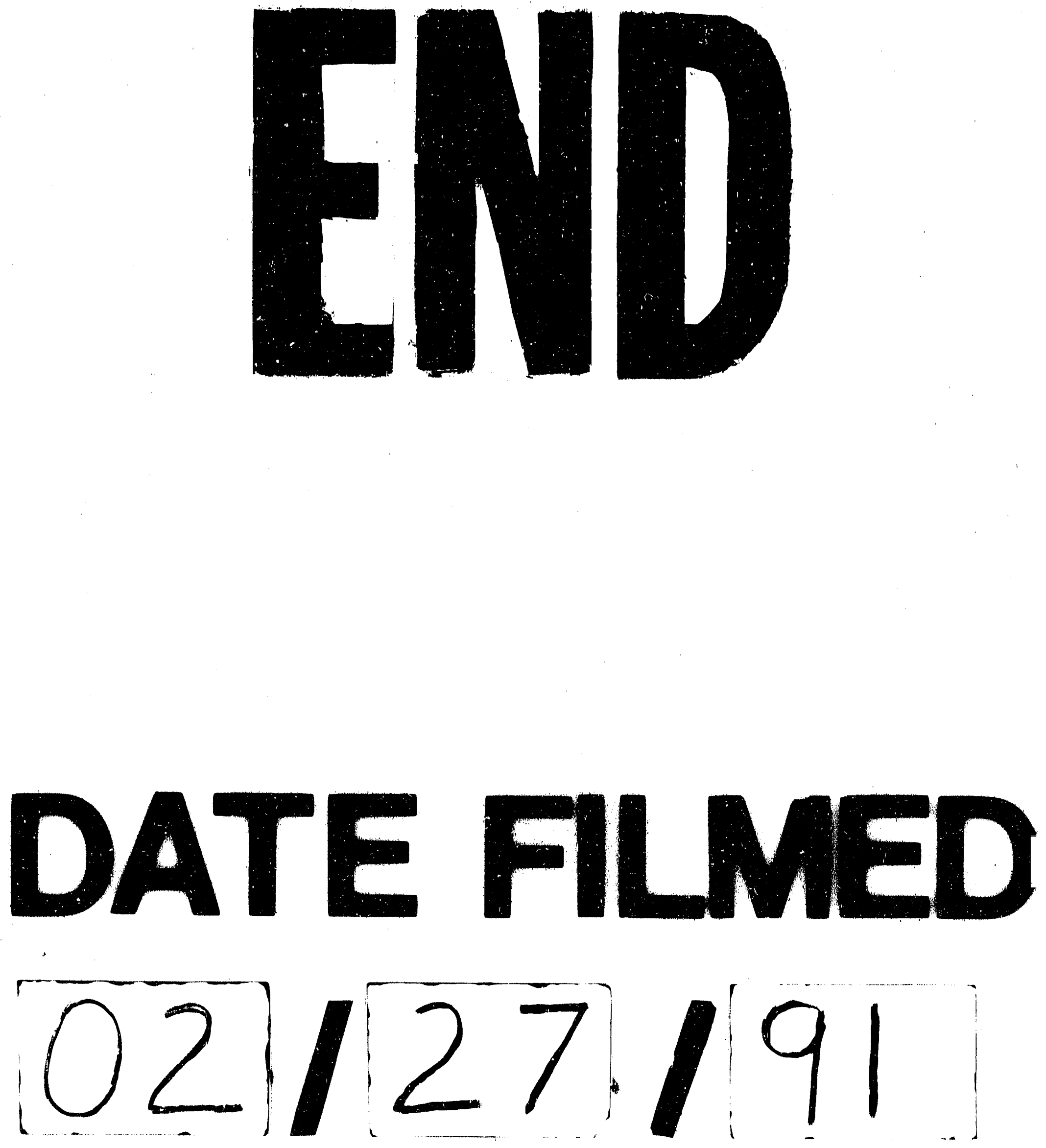
